\title{
INVESTIGATIONS ON FORCE GENERATION AND JOINT PROPERTIES OF DISSIMILAR THICKNESS FRICTION STIR CORNER WELDED AA 5086 ALLOY
}

\author{
Manigandan Krishnan $^{1 *}$, Senthilkumar Subramaniam ${ }^{1}$ \\ ${ }^{1}$ School of Mechanical Engineering, VIT University, Vellore-632014, Tamilnadu, India
}

\begin{tabular}{l} 
ARTICLE INFO \\
\hline Article history: \\
Received: 21.12 .2017$. \\
Received in revised form: 14.05.2018. \\
Accepted: 13.06 .2018$. \\
\hline Keywords: \\
Friction stir welding \\
Corner joint \\
Dissimilar thickness \\
Microstructure \\
Tensile strength \\
Hardness \\
\hline
\end{tabular}

DOI: http://doi.org/10.30765/er.40.1.09

\begin{abstract}
:
The force generation, joint mechanical and metallurgical properties of friction stir corner welded non-heat treatable AA 5086 aluminum alloy are investigated in this paper. The friction stir welding process is carried out with the plate thicknesses of $6 \mathrm{~mm}$ and $4 \mathrm{~mm}$. The welding speed, tool rotational speed and tool plunge depth were considered as the process parameters to conduct the welding experiments. The machine spindle motor current consumption and tool down force generation during friction stir welding were analyzed. The microstructures of various joint regions were observed. The tensile samples revealed the tensile strength of $197 \mathrm{MPa}$ with tool rotational and welding speeds of 1,000 rev/min and $150 \mathrm{~mm} / \mathrm{min}$ respectively, which is $78 \%$ of parent material tensile strength. A maximum micro hardness of $98 \mathrm{HV}$ was observed at thermomechanically joint affected zone, which was welded with tool rotation of $1,000 \mathrm{rev} / \mathrm{min}$ and welding speed of $190 \mathrm{~mm} / \mathrm{min}$.
\end{abstract}

materials around the tool pin. The maximum temperature during welding is usually less than $80 \%$ of the melting temperature of materials. AA 5086 is a non heat treatable alloy that exhibits higher strength to weight ratio, has good ductility and good corrosion resistance which is widely used to fabricate marine, transportation equipments and missile components. The FSW can be applied for different joint designs, such as Butt joint, T-joint, lap joint and corner joint. In corner joints, the materials to be welded are clamped right angle to one another during the FSW welding.

Friction stir welding of similar and dissimilar AA7075 and AA5083 were investigated by Ahmed et al [1]. The increase in welding speed from 50 $\mathrm{mm} / \mathrm{min}$ to $200 \mathrm{~mm} / \mathrm{min}$ occurred, and the average

\footnotetext{
* Corresponding author. Tel.:+919894222756

E-mail address: manivitphd@gmail.com
} 
grain size was decreased. The joints revealed ultimate tensile strengths of $267 \mathrm{MPa}$ with joint efficiencies between 77 and $87 \%$ of the AA 5083 alloy parent material. Byung and Yong [2] fabricated SiCp /AA 5083 composite via friction stir welding. Micro hardness at the weld zone was higher with $\mathrm{SiC}$ particles than that of without $\mathrm{SiC}$ particles. The result was reduction in the grain size and aluminum matrix strengthened the $\mathrm{SiC}$ particles. Dorbane et al [3] investigated mechanical, microstructural and fracture properties of dissimilar welds produced by friction stir welding of AZ31B and AA 6061. Lakshminarayanan et al [4] studied the characteristics of friction welded AZ31B magnesium with commercial pure titanium dissimilar joints. Martin et al [5] studied the techniques for welding corner joints using friction stir welding. The corner joint of AA 6082-T6 alloy was fabricated with the stationary shoulder rotating tool with filler material. However, the AA 5083-O joints failed at the base material regardless of the filler material used. The highest tensile strength of $310 \mathrm{MPa}$ was obtained in AA 5083-O corner joints. Srinivasarao et al [6] studied the microstructure and mechanical properties of friction stir welded AA 7075-T651 aluminum alloy thick plates. Yong et al [7] studied dissimilar friction stir welding between 5052 aluminum alloy and AZ 31 magnesium alloy. The uneven distribution of the hardness profile was most extreme in the weld zone and was twice higher than that of the base material. The rotation speed of $600 \mathrm{rev} / \mathrm{min}$ and the welding speed of $40 \mathrm{~mm} / \mathrm{min}$ produced better joint properties. Klobcar et al [8] investigated the microstructure and mechanical properties of the friction stir welded $\mathrm{Al} / \mathrm{Mg}$ alloy and observed that a good FSW weld had smooth apex surfaces and filled weld root, while the weld surface was slightly depressed for $0.2 \mathrm{~mm}$. When the FSW tool was used for welding approximately $0.2 \mathrm{~mm}$ under the base material surface, a welding force in the Z-direction was high sufficient to produce better welds without worm hole defects.

From the comprehensive literature review, it is found that there is limited research on the investigation of corner joints on friction stir welding especially dissimilar thickness corner joints. So an attempt has been made to fabricate dissimilar thickness corner joints using the non-heat treatable AA 5086 aluminium alloy at the different combination of process parameters.

\section{Experimental work}

Aluminum alloy AA 5086 plates are joined using the friction stir welding process in order to analyze the joint mechanical and metallurgical properties. The chemical composition and mechanical properties of the AA 5086 alloy are shown in Table 1 \& Table 2.

Table 1. Chemical composition (wt \%) of AA 5086 aluminum alloy.

\begin{tabular}{|c|c|c|c|c|c|c|c|}
\hline Alloy & $\mathrm{Cr}$ & $\mathrm{Cu}$ & $\mathrm{Fe}$ & $\mathrm{Mg}$ & $\mathrm{Mn}$ & $\mathrm{Si}$ & $\mathrm{Al}$ \\
\hline AA5086 & 0.08 & 0.05 & 0.4 & 4.3 & 0.4 & 0.3 & Bal. \\
\hline
\end{tabular}

Table 2. Mechanical properties of AA 5086 aluminum alloy.

\begin{tabular}{|l|l|}
\hline Mechanical Property & AA 5086 alloy \\
\hline Ultimate tensile strength & $250 \mathrm{MPa}$ \\
\hline Yield strength & $212 \mathrm{MPa}$ \\
\hline Elongation & $21 \%$ \\
\hline
\end{tabular}

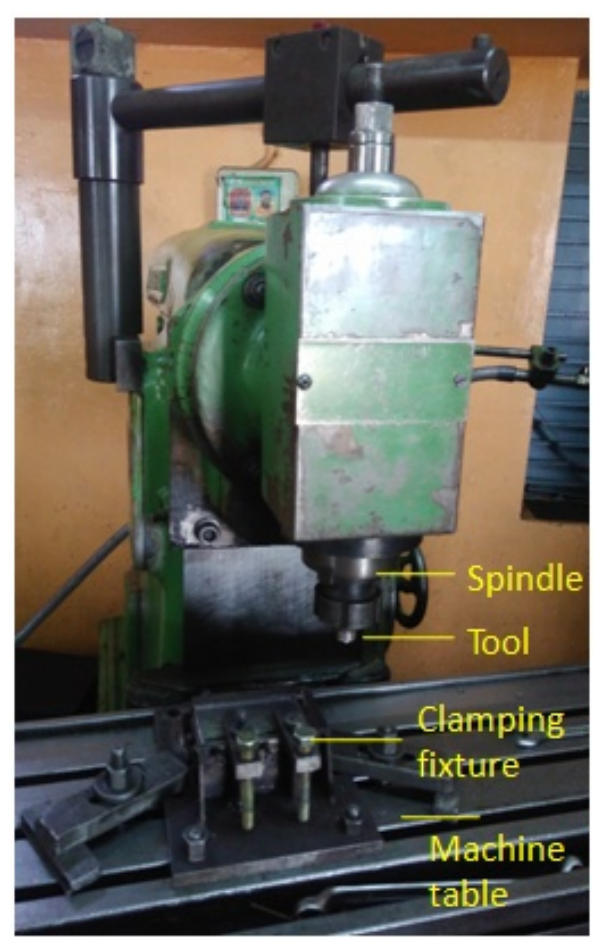

Figure 1. The FSW experimental setup.

FSW specimens with dimensions of $100 \mathrm{~mm} \times 50$ $\mathrm{mm} \times 6 \mathrm{~mm}$ and $100 \mathrm{~mm} \times 50 \mathrm{~mm} \times 4 \mathrm{~mm}$ were prepared from the rolled plates of AA 5086 alloy. A rotational tool with shoulder diameter of $18 \mathrm{~mm}$ and cylindrical threaded profiled pin with $3.7 \mathrm{~mm}$ length 
was preferred to be carried out in the joining process. The tool was machined from D2 tool steel and heat treated to 58 HRC. The experimental setup to fabricate dissimilar thickness corner joints with modified vertical milling machine (HMT INDIA), is shown in Fig. 1. The joints were welded at three distinctive parameters, such as rotational speeds of 900, 1,000 and $1,100 \mathrm{rev} / \mathrm{min}$, welding speeds of 100, 150 and $190 \mathrm{~mm} / \mathrm{min}$ and plunge depth of 0.1 $\mathrm{mm}, 0.2 \mathrm{~mm}$, and $0.3 \mathrm{~mm}$. Table 3 shows the $\mathrm{L}_{09}$ orthogonal array, which was adopted as a design of the experiments.

Table 3. L9 orthogonal array.

\begin{tabular}{|c|c|c|c|}
\hline $\begin{array}{c}\text { Exp. } \\
\text { No. }\end{array}$ & $\begin{array}{c}\text { Rotation } \\
\text { speed } \\
\text { (rev/min) }\end{array}$ & $\begin{array}{c}\text { Welding speed } \\
(\mathrm{mm} / \mathrm{min})\end{array}$ & $\begin{array}{c}\text { Plunge } \\
\text { depth } \\
(\mathrm{mm})\end{array}$ \\
\hline A & 900 & 100 & 0.1 \\
\hline B & 900 & 150 & 0.2 \\
\hline C & 900 & 190 & 0.3 \\
\hline D & 1000 & 100 & 0.2 \\
\hline E & 1000 & 150 & 0.3 \\
\hline F & 1000 & 190 & 0.1 \\
\hline G & 1100 & 100 & 0.3 \\
\hline H & 1100 & 150 & 0.1 \\
\hline I & 1100 & 190 & 0.2 \\
\hline
\end{tabular}

The schematic of experimental setup for dissimilar thickness friction stir welding for corner joint is shown in Fig. 2.

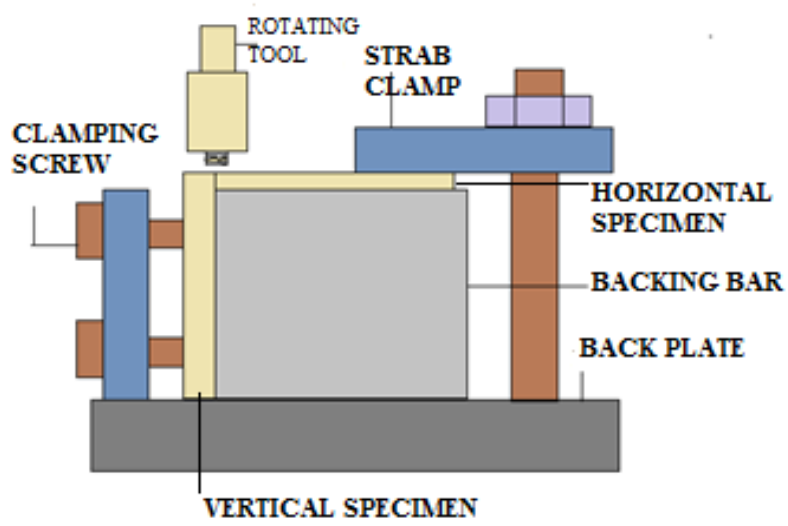

Figure 2. Schematic of the FSW of corner joint.

A fixture was fabricated as depicted in Fig. 3, for locating and clamping the FSW specimens. The tool was rotated clockwise direction during welding.

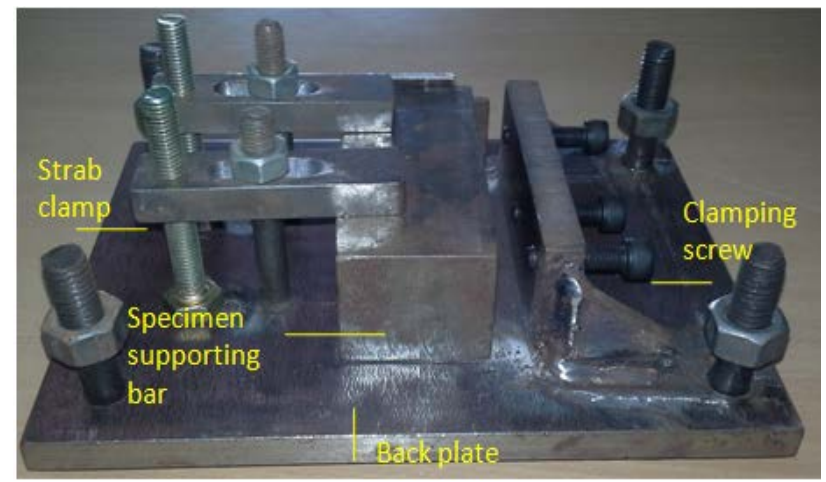

Figure 3. The FSW fixture.

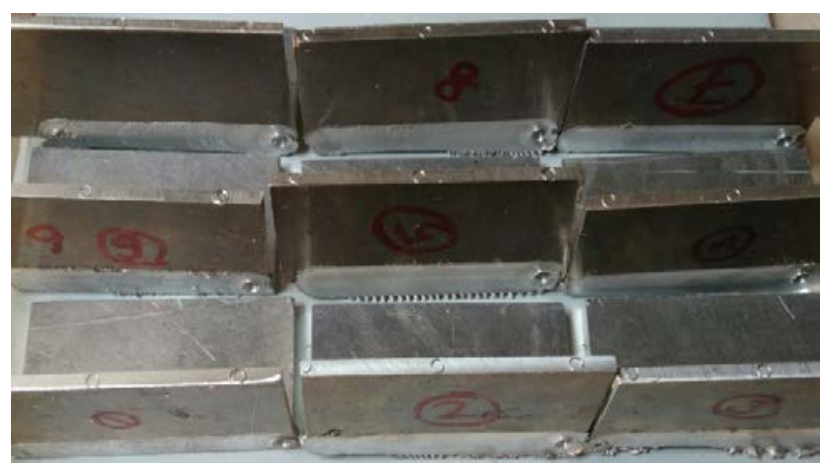

Figure 4. Dissimilar thickness friction stir corner joints.

The corner welded AA 5086 plates are shown in Fig. 4. The test samples were cut from the welded plates normal to weld line to carry out microstructural characterization. The samples were etched with Keller's reagent according to the standard metallographic procedure. The microstructures of the weld were observed using an optical microscope (OLYMPUS-BX61) and scanning electron microscope (HITACHI-S3400N). The tensile test specimens were prepared in the direction of normal to the weld joint. Three test samples were prepared from every joint and the mean value was considered for further investigation. The ultimate tensile strength (UTS) was estimated using a computerized universal testing machine (INSTRON-8801). A specially designed clamp was utilized to hold the tensile samples in the UTM. The fractured surfaces of the tensile samples were analyzed with the Scanning Electron Microscope. The Vickers micro hardness analyzer (METCO) was used to measure the hardness along the transverse direction of the weld joint with the load of $50 \mathrm{~g}$ and dwell time of $15 \mathrm{~s}$. The FSW machine spindle motor electric current consumption during welding was measured using clamp meter (Mastech M266 Digital 
AC). The jaws of the clamp meter were clamped over the power cable of the FSW machine tool during welding.

\section{Results and discussion}

\subsection{Electric current consumption}

The electric current flow through the motor is estimated during welding at various stages of the friction stir welding.

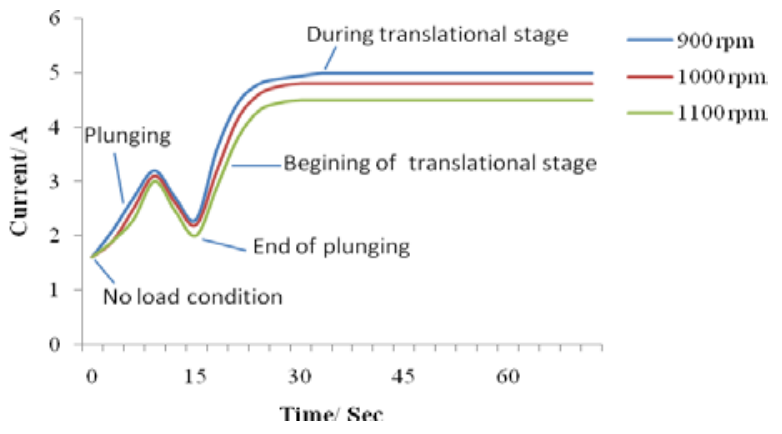

Figure 5. Electric current consumption during the FSW at the welding speed of $100 \mathrm{~mm} / \mathrm{min}$.

Fig. 5 reveals current flow through the motor at the rotation speeds of $900,1,000$ and 1,100 rev/min and constant welding speed of $100 \mathrm{~mm} / \mathrm{min}$. Senthilkumar et al [9] investigated a machine spindle motor current of friction stir butt welded aluminium alloy flat plates, which perfected with the present work. The first value of current $1.6 \mathrm{~A}$ was observed at no load condition when the auxiliary motors such as hydraulic pump, and electrical motors were turned on. During the plunging stage the current flow gets increased rapidly reaching the value of $2.7 \mathrm{~A}$, and during the tool shoulder it contacts the surface of the material. Then the current gradually decreases due to material relaxing by frictional heat generation by the stirring action of the tool. At the beginning of the translational stage, the motor current increased rapidly to $4.8 \mathrm{~A}$, while the tool is experienced colder material on traverse. Then it remained steady till the end and decreased to the value of no-load condition on tool retreat from work material. It is found that the current flow is increased to $4.8 \mathrm{~A}$ at the lower rotational speed of

$900 \mathrm{rev} / \mathrm{min}$ and decreased to $4.4 \mathrm{~A}$ at the higher rotational speed of $1,100 \mathrm{rev} / \mathrm{min}$.

\subsection{Force generation}

The friction stir welding tool experiences transverse, longitudinal and downward forces at $\mathrm{X}, \mathrm{Y}$ and $\mathrm{Z}$ directions during the welding process. Trimble and Monaghan [10] had studied force generation during friction stir welding of AA 2024-T3. In the present work, the force generated during the FSW of corner joint of AA 5086 was measured using strain gauge.

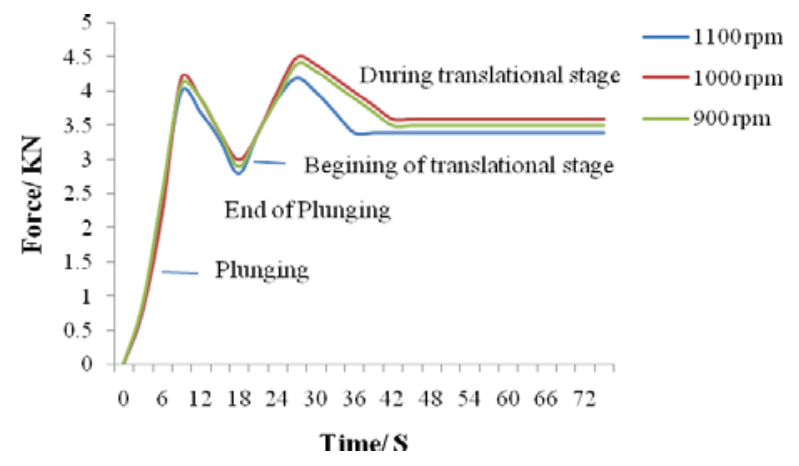

Figure 6. Downward force generation at the welding speed of $100 \mathrm{~mm} / \mathrm{min}$.

Fig. 6 depicts the down force produced at the constant welding speed of $100 \mathrm{~mm} / \mathrm{min}$ and different rotational speeds of 900, 1,000 and 1,100 $\mathrm{rev} / \mathrm{min}$. The variation in process parameters has an impact on the force generation during the FSW. The downward force reached peak values of $4.3 \mathrm{kN}$ and $4.5 \mathrm{kN}$ during plunging and beginning of the translational stage because the tool encounters the colder material at the rotational speed of 900 $\mathrm{rev} / \mathrm{min}$. The force is reduced significantly and remained steady with value of $3.7 \mathrm{kN}$ during the translational stage until the end of the weld. The tool shoulder is the principle driving element of downward force. The downward force is increased with lower rotational and higher welding speeds because of the low thermal softening of the material.

\subsection{Microstructural characterization}

Ilangovan et al [11] studied the effect of a tool pin profile on microstructure and tensile properties of the friction stir welded dissimilar AA 6061/AA 5086 aluminium alloy joints. The present work analyses microstructural characterization of corner welded AA 5086 aluminum alloy joints. The defects are not observed in the weld zone and macrograph of the corner joint is shown in Fig. 7. 


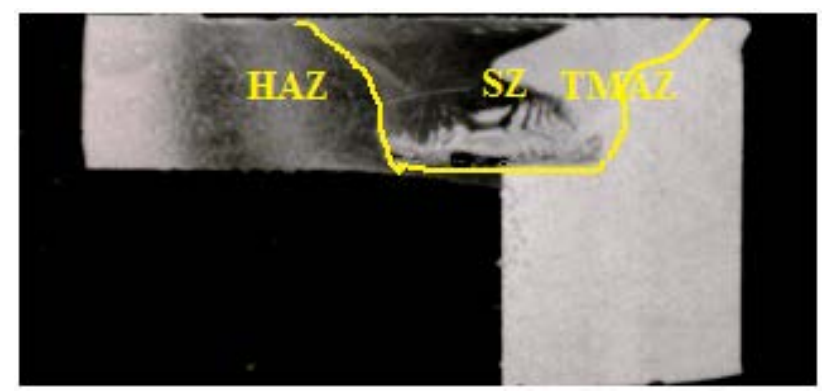

Figure 7. Macrograph of the FSW corner joint.

Fig. 8 shows the optical micrographs of the weld zone. Three distinct zones are identified such as stir zone, thermomechanically affected zone (TMAZ), and heat affected zone from the microstructural examinations. Fig. 8(a), Fig. 8(b), Fig. 8(c) and Fig. 8(d) demonstrate the microstructure of parent material, heat affected zone, thermomechanically affected zone and stir zone. The grain structures of the parent material and heat affected zone are similar because of low thermal affectability. The boundary between the weld zone and the thermomechanically affected zone can be seen clearly. Thermomechanically, the affected zone indicates highly extended grains of the aluminium alloy without recrystallization. Both sides of the thermomechanically affected zone reveal the similar grain structure. It was noticed that the microstructure of the stir zone and heat affected zone are separated by the TMAZ. The thermo mechanically affected zone was thermally affected and plastically deformed but not recrystallized. The stir zone experienced the high temperature and heavy plastic deformation during the welding. It results in fine-equiaxed recrystallized grains followed by dynamic recrystallization, which increases the strength of the weld.

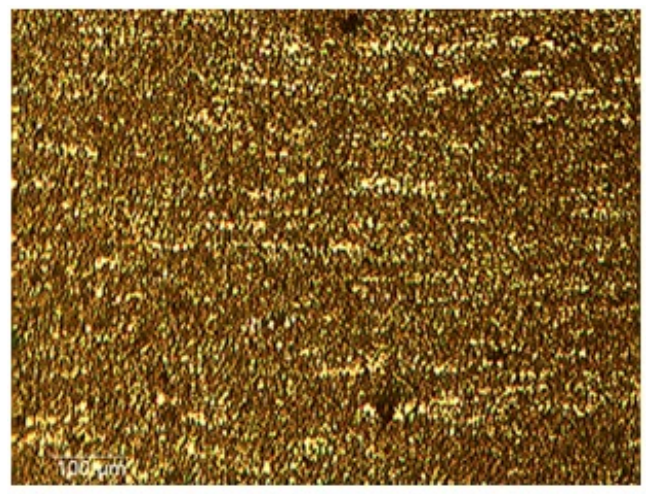

(a) Base metal AA $\mathbf{5 0 8 6}$

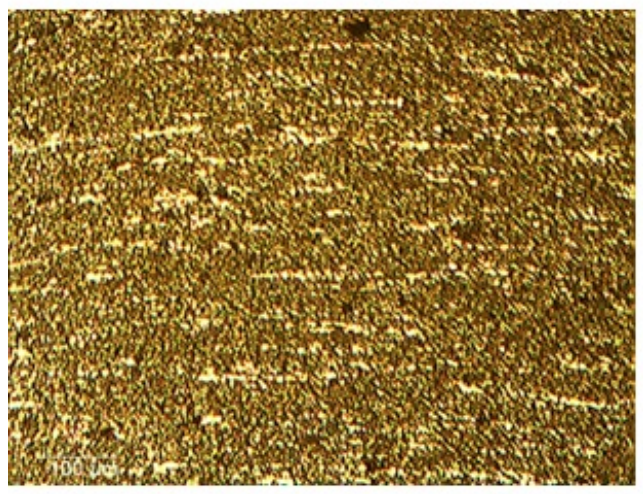

(b) Heat affected zone

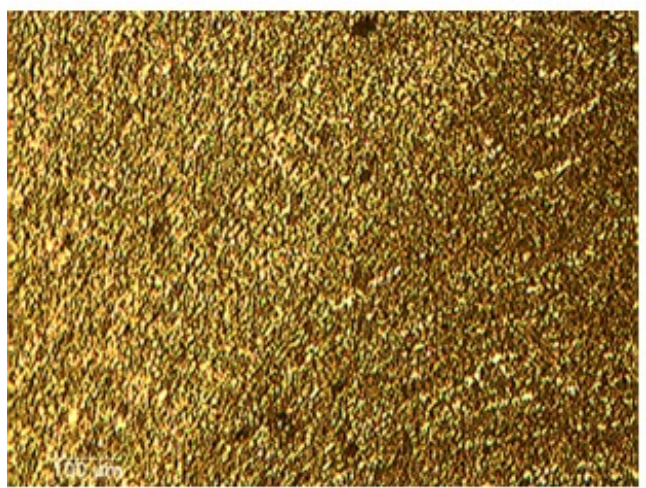

(c) Thermo mechanically affected zone

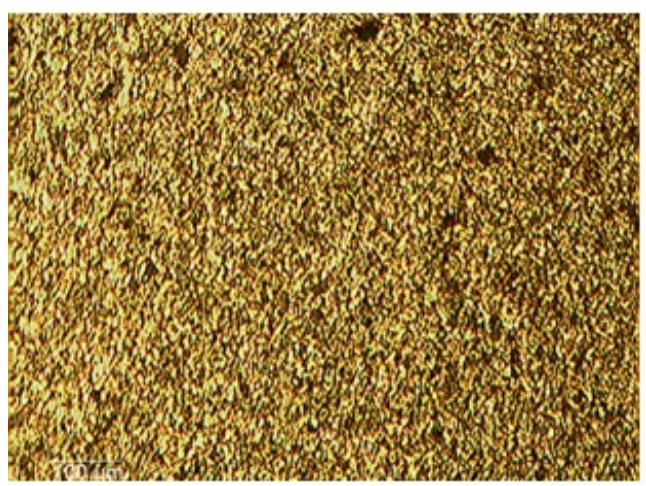

(d) Stir zone

Figure 8. Optical micrographs at the welding and rotational speeds of $100 \mathrm{~mm} / \mathrm{min}$ and $1,100 \mathrm{rev} / \mathrm{min}$. 


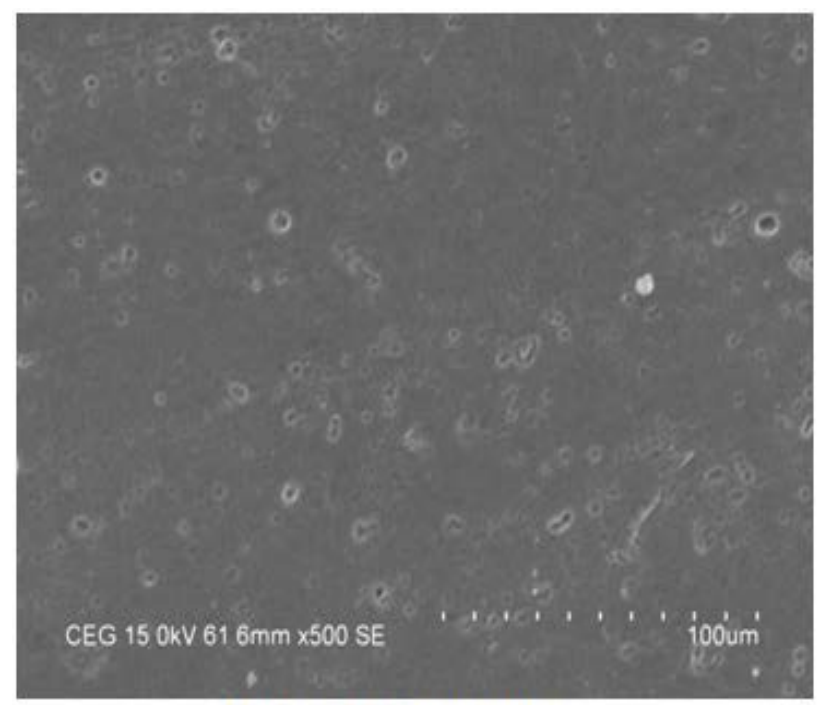

(a) Base Metal AA 5086

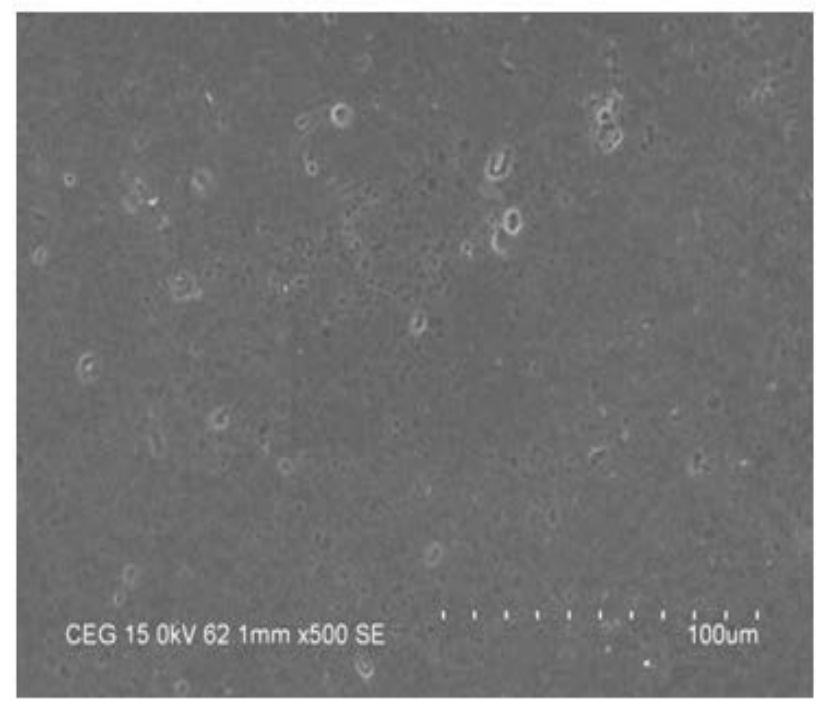

(b) Stir zone

Figure 9. SEM micrographs.

Fig. 9(a) and Fig. 9(b) illustrate the SEM micrographs of the base material and stir zone, fabricated at the rotational speed of $1,000 \mathrm{rev} / \mathrm{min}$ and welding speed of $150 \mathrm{~mm} / \mathrm{min}$. Fig. 9(b) reveals microstructure of the stir zone, which indicates the broken precipitates found in the stirred zone due to severe deformation of the material during the FSW process. The typical grain size in the weld zone was around 12 to $15 \mu \mathrm{m}$, which was much smaller than the parent material. The particle size of the weld zone is decreased with increasing welding speeds.

\subsection{Tensile properties}

The results demonstrate that the tensile properties of the welded joints remarkably fluctuating with respect to different welding and rotational speeds. The higher tensile strength of $197 \mathrm{MPa}$ is achieved in the weld joint, fabricated at the process parameters of $1,000 \mathrm{rev} / \mathrm{min}$ rotational speed and $150 \mathrm{~mm} / \mathrm{min}$ welding speed, which is equal to $78 \%$ of the unwelded parent material. The lower tensile strength of $151 \mathrm{MPa}$ is obtained in the weld joint, fabricated at $900 \mathrm{rev} / \mathrm{min}$ of rotational speed, 100 $\mathrm{mm} / \mathrm{min}$ of welding speed, which is equal to $60 \%$ of the unwelded AA 5086 aluminum alloy. A significant increase in welding speed improves the weld quality and mechanical properties. The effect of welding speed on tensile strength of the joints is shown in Fig. 10. The lower tensile strength was obtained at the lower and the higher welding speeds of 100 and $190 \mathrm{~mm} / \mathrm{min}$. The joints fabricated at the lower welding speed produce high temperature, but low cooling rate followed by coarsening of grains. The reduction of the ultimate tensile strength and higher welding speed cause insufficient stirring. Thus lower heat generation with faster cooling rate subsequently lower the ultimate tensile strength. The welding speed influences the plasticization of the material, grain size, and defects [12]. All the samples are broken at heat affected zone during the tensile test.

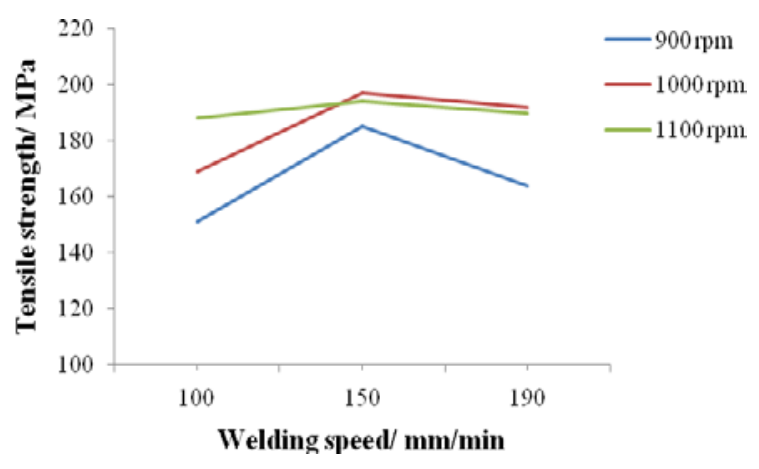

Figure 10. Effect of welding speed on ultimate tensile strength.

\subsection{Micro hardness}

Fig. 11 illustrates the micro hardness profiles of the FSW AA 5086 aluminium alloy at various welding speeds of 100, 150, and $190 \mathrm{~mm} / \mathrm{min}$ and constant rotational speed of $1,000 \mathrm{rev} / \mathrm{min}$. It is observed that the lower welding speed produces the higher 
hardness values in the weld zone. The micro hardness profile has reached maximum value of 98 $\mathrm{HV}$ at TMAZ at the welding speed of $190 \mathrm{~mm} / \mathrm{min}$ and minimum hardness value of $80 \mathrm{HV}$ is observed at TMAZ at the welding speed of $100 \mathrm{~mm} / \mathrm{min}$. The average Vickers hardness value was $91 \mathrm{HV}$. The mechanical properties are extremely affected by the thermal conditions of the welding. Moreover, it is found that the hardness value of the retreating side was comparatively higher than that of the alternative side. The higher value of the micro hardness is obtained in the stir zone range in comparison to the heat affected zone and thermomechanically affected zone due to grain refinement. The lower micro hardness values are recorded at the heat affected zone rather than the parent material. The welding speed greatly affects the microstructure results and it influences the micro hardness distribution [13 \&14].

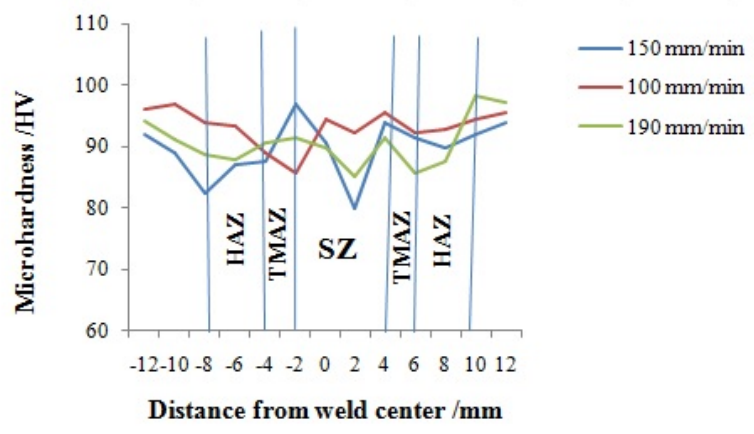

Figure 11. Micro hardness of the FSW joints produced at the rotational speed of 1,000 $\mathrm{rev} / \mathrm{min}$.

\subsection{Fractographs}

Fig. 12 illustrates the SEM fractographs of the fractured surfaces of high strength FSW specimen after the tensile test, fabricated at the welding speed of $150 \mathrm{~mm} / \mathrm{min}$ and the rotational speed of 1,000 rev/min. Fig. 12(a) demonstrates the large-scale view of the fractured surface that indicates a homogeneously rough surface. The ductile fractured feature with voids nucleation and coalescence is observed in the enlarged view of the fractured surface. A large number of dimples with different depth indicated that a ductile fracture occurred in these regions. These dimples are responsible for fracture at the heat-affected zone [15].

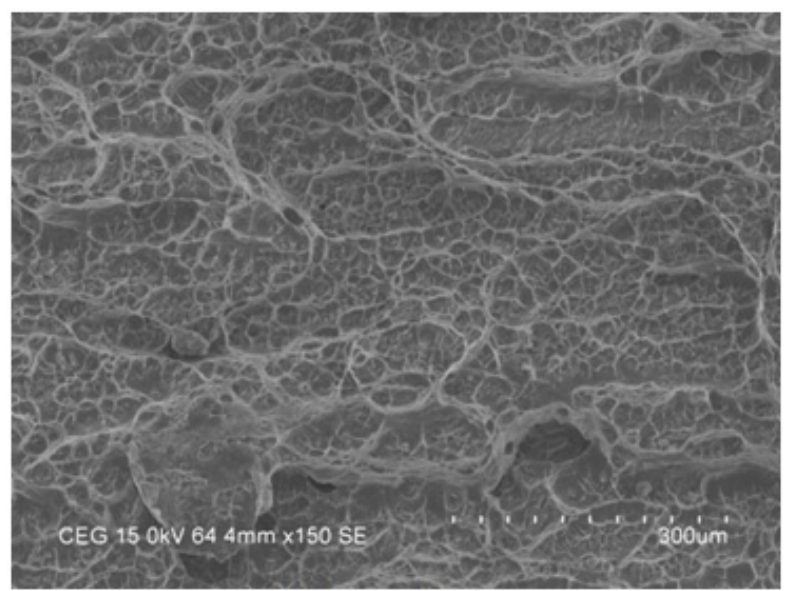

(a) Enlarged view

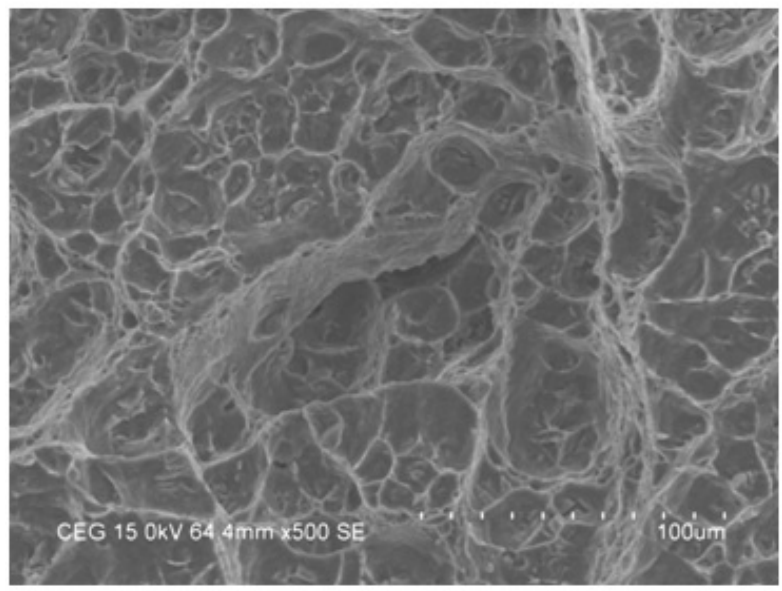

(b) Heat affected zone

Figure 12. Fractographs of the FSW specimen with the welding speed of $150 \mathrm{~mm} / \mathrm{min}$ and the rotational speed of 1,000 rev/min.

\section{Conclusions}

The FSW of the corner joint of AA 5086 aluminum alloy plates is studied in this experimental work. The corner weld joint produced at welding speed of $150 \mathrm{~mm} / \mathrm{min}$ and the tool rotational speed of 1,000 $\mathrm{rev} / \mathrm{min}$ is defect-free and shows the better mechanical and metallurgical properties. Furthermore, the surface morphology of the weld zone is well developed with an increase of the tool rotation speed. A higher joint tensile strength of 197 $\mathrm{MPa}$ is obtained, which is $78 \%$ of strength of the parent material. A lower joint tensile strength of 151 $\mathrm{MPa}$ is obtained, which is $60 \%$ of strength of the base material.

Hardness at the stir zone is higher than the base material, because of noteworthy grain refinements. The maximum hardness is observed as $98 \mathrm{HV}$ at 
thermomechanically affected zone. The fracture positions of all joints are located at the heat affected zone, which reveals defect-free weld zones.

Electric current consumption and tool down force generation of the FSW machine tool were studied during noload, tool plunge and traversing stages of the FSW process. A motor electric current of $1.6 \mathrm{~A}$, 2.7 $\mathrm{A}$ and $4.8 \mathrm{~A}$ at no load, plunging of the tool and the translational stage of the FSW process has been observed respectively. The FSW tool downward force is observed as $4.3 \mathrm{kN}$ during plunging and 4.5 $\mathrm{kN}$ at beginning of the tool translation and a steady state value of $3.7 \mathrm{kN}$ during the translational, until the end of the weld process.

\section{References}

[1] Ahmed, M.M.Z., Sabbah Ataya, El-Sayed Seleman, M.M.: Friction stir welding of similar and dissimilar AA7075 and AA5083, Jour. of Mat. Proc. Tech., 242 (2017), 77-91.

[2] Byung Wook, Yong Hwan Kim: Fabrication of SiCp/AA5083 composite via friction stir welding, Trans. Nonferrous Met. Soc. China, 22 (2012), s634-s638.

[3] Dorbane, A., Ayoub, G., Shunmugasamy, V.C.: Mechanical, microstructural and fracture properties of dissimilar welds produced by friction stir welding of AZ31B and Al6061, Materials Science \& Engineering, A651 (2016), 720-733.

[4] Lakshminarayanan, A.K., Saranarayanan, R., Karthik Srinivas, V.: Characteristics of friction welded AZ31B magnesium-commercial pure titanium dissimilar joints, Journal of Magnesium and Alloys, 3 (2015), 315-321.

[5] Martin, J.P., Stanhope, C., Gascoyne, S.: Novel techniques for corner joints using friction stir welding, TMS Annual Meeting \& Exhibition,USA, 2011,

[6] Srinivasarao, T., Madhusudhanreddy, G., Koteswararao, S.R.: Microstructure and mechanical properties of friction stir welded AA7075-T651 aluminum alloy thick plates, Trans. Nonferrous Met. Soc. China, 25 (2015), 1770-1778.

[7] Yong Y., Cheng Q., Wen Z.: Dissimilar friction stir welding between 5052 aluminum alloy and AZ31 magnesium alloy, Trans. Nonf. Met. Soc. China, 20 (2010), s619-s623.

[8] Klobcar D., Kosec L., Pepelnjak T., Tusek J.: Microstructure and mechanical properties of friction stir welded $\mathrm{Al} / \mathrm{Mg}$ 4.5 Mn alloy, Engineering Review, 32 (2012), 2, 104-110.

[9] Senthilkumar, S., Denis Ashok S., Narayanan S.: Investigation of Friction Stir Butt Welded Aluminium Alloy Flat Plates using Spindle Motor Current Monitoring Method, Procedia Engineering (2013) 91-95.

[10] Trimble, D., Monaghan, J.: Force generation during friction stir welding of AA2024-T3, Manufacturing Technology, 61 (2012), 9-12.

[11] Ilangovan, M., Rajendraboopathy, S., Balasubramanian, V.: Effect of tool pin profile on microstructure and tensile properties of friction stir welded dissimilar AA 6061-AA 5086 aluminium alloy joints, Defence Technology, 11 (2015), 74-84.

[12] Dinaharan, I., Murugan, N.: Effect of FSW on microstructure, mechanical and wear properties of AA6061/ZrB2 cast composite, Mat. Sci. and Eng., A543 (2012), 257-266.

[13] Noor Zaman Khan, Zahid Khan: The mechanical and microstructural behavior of friction stir welded similar and dissimilar sheets of AA2219 and AA7475 aluminium alloys, Journal of Alloys and Compounds, 695 (2017), 2902-2908.

[14] Palanivel, R., Koshy Mathews, P., Dinaharan, I.: Mechanical and metallurgical properties of dissimilar friction stir welded AA5083-H111 and AA6351-T6 aluminum alloys, Trans. Nonferrous Met. Soc. China, 24 (2012), 58-65.

[15] Rodriguez, R.I., Allison, P.G.: Microstructure and mechanical properties of dissimilar friction stir welding of 6061-7050 aluminium. Alloys, Mat. \& Des., 83 (2015), 60-65. 